\title{
Disenchantment and Transcendence
}

\author{
Discussion on the Contemporary Block Prints
}

\author{
Mingjuan Li \\ School of Architecture \& Allied Arts \\ Guangzhou Academy of Fine Arts \\ Guangzhou, China
}

\begin{abstract}
This paper has a topic of discussion on the contemporary block print art creation. The contemporary block print is in a rising development, and in the past 20 years of practice, technology and artistry have always been a necessary topic in the block print industry. This paper attempts to verify the relationship between the two from the perspective of tradition, future and society, and it also makes verification and analysis on the development of block print technology and the contemporaryity and value presentation of artistic language, and it also further points out that we must combine the new technologies and ideas to make a transcendence in the accumulation of traditional technology, and when technology reaches a level of perfection, concepts and ideas can be freely presented. As a result, technology is no longer a "protagonist," but a powerful back support for conceptual expression.
\end{abstract}

Keywords—block prints; contemporaryity; technology; disenchantment

\section{INTRODUCTION}

China has the glorious history of the earliest invention of engraving and printing in the world, and the tradition of block print is long and profound, while from the perspective of modern and contemporary art, the development of Chinese block print is late.

All the things related to contemporaryity seem to represent avant-garde, forward-looking, and futuristic features, while woodcut prints are traditional Chinese art styles, and due to their nativeness and technical convenience, they have become the art style with the most "contemporary" value in the Chinese New Culture Movement. In the past, the current and the future, the identity change of art style is always full of dramatic features, but also inevitability. In modern bock prints, besides woodcuts and watermarks, other categories are derived from the West and are imported. During these skills entering the art of painting from the practical field in China, and even in the field of contemporary art, they need the upgrading in technology but also the improvement in culture and function. This process is not easy, and due to the constraints of technical factors and the later exploration and congnition of artistic language, the expansion from inside to outside always seems a little powerless, which made the influence of block prints little and weak in contemporary art. In the discussion on the contemporary features of block print, the technology and art like a teeterboard is naturally become the focus. In many arguments, I am more inclined to believe that technology and art are not in a relationship of wane and wax. "Truely, artistic craftsman are almost considered to be a denial of this proposition for artists, which is a paradox for the art tradition, because the craftsmen know all the rules and knacks, but they can't see that their competitors are not the artists throughout the ages but the perfect idea of Plato style, and this perfect idea always requires more and more efforts to study the issues." [1] Gombrich talks about the relationship between technological transcendence and art, while Yan $\mathrm{Yu}$ in the Southern Song Dynasty also has a famous saying: "Antelope hanging its horn, no trace can be found" [2], this is a gradual argumentation for the poetics in the Song Dynasty, focusing on skills, far from the remembrance and sigh in the representative poetries at highest realm "since the Wei, Jin, Han and Tang dynasties". $\mathrm{He}$ believes that $\mathrm{Li}$ Bai and $\mathrm{Du} \mathrm{Fu}$ have the skills of writing in their poetries not surpassed by others, without too literal interpretation, or trace, but with true temper expressed. He is talks about the technology without boundaries and presents reasonable problems without skill flaunted, making the inner "poetic" highlighted. In my opinion, both are truths that can serve as the two basic supports of this topic, and the later is premised on the former.

\section{PResentation of TeChnicAl AND ARtistic Value}

The real development of contemporary Chinese block print has not lasted more than a hundred years since the new woodcut movement and it has been confronted with two major puzzles: technical puzzlement and language puzzlement. In the history of Western art, block print has undergone a series of technological elimination and replacement processes for the needs of direct drawing. The first to be marginalized is the woodcut print. Copperplate prints, lithographs, and silkscreen prints are all artistic styles derived from the progress of science and technology. However, in China, the opposite is true. Because of the unfairness of cultural sources and technical soils, these western-style editions have long been technically one of the barriers to the development of Chinese print art. Until the last two decades, with the continuous efforts of academic block print and the strengthening of international exchanges, the technical barriers to block print have gradually collapsed. "Especially the research block print of the academy has achieved remarkable results, and the printmaking technology, language and concepts have been comparable to the international level."[3] "The part of our vision has obviously reached a very high level, and the part I emphasize 
refers to block print material, toothbrush effect, technical difficulty of the print, and the clarity of personal form language, etc." [4] From the comments of the 4th Guanlan International Biennial Block Print Exhibition, it can be seen that the progress and continuous advancement of printmaking technology level has a direct relationship with art and contemporary expression. At the same time, the curator also raised the prevalent alarm about the aesthetic tendency of technicalization. "“Technological supremacy' is still a secret rule in printmaking circles. Content has become an excuse, so that there are some shortcomings in the artistry above the printmaking language..." [5] This kind of vigilance received a certain response in the subsequent 5th Biennale. "In the first one or two biennales, the Chinese exhibits were significantly different from the international prints... but in the justconcluded 5th Guanlan International Biennial Block Print Exhibition, this gap was barely noticed... Some young and middle-aged artists' works had a clearer artistic orientation, so that they could really achieve some academic exchanges with international artists from the perspective of art."'[6]

This change is exciting. Over the past 20 years, there have been too many printmaking circle creators "leaving". In different art categories, painting fields and design fields, there are many outstanding practitioners and artists who have stepped out of printmaking kingdom. But behind the reputation of "cross-domain", more "leaving" stems from helplessness.

From the external environment, compared with oil paintings representing western traditional styles and traditional Chinese paintings standing for Chinese traditional culture, block print has long been in a "small circle" in the art field; in the eyes of the public, block print is a minority art. From longterm observation, the reasons for the minority of prints can be roughly summarized as follows: First, the long-term immaturity of technical system makes it easier that excellent works will attract attention. In the long run, this overall aesthetic tendency has formed a collective suggestion of technical priority in the way of interpretation of works, namely, triteness, craftsmanship and materials and decoration are better than the whole artistry. Secondly, "the development of Chinese printmaking in the past 20 years seems to be a hermit in the city, hardly affected by the crazy growth of Chinese art market over the past 2 decades."[7] The retreat in the market is not only due to the unclear artistic value standards related to the plural concept of printmaking, but also owing to the methods simplicity of the mature works entering the market. The public lacks the guidance of appreciation and interpretation. Most people think that block print just means a woodcut or a copy of celebrity handwriting. Market factors and the survival space of original prints are mainly supported by academy and official exhibitions.

From the perspective of academic circles, with relatively complete equipment and studios, higher professional colleges are the main carrier and platform for domestic block print art and academics. However, the discipline of block print is largely unconsciously restricted by technical systems. This restriction is reflected in the fact that on the one hand, people strive to expand printmaking to contemporary art, such as cross-domain attempts, abandoning the pursuit of plurals, eliminating the complexity of the process in exchange for a quick and direct creative pleasure. At the same time, because of the limited technical and academic resources of the college platform, it is difficult to provide a relatively mature and sustainable technology platform system for teachers and students. Limited by the help of the workspace and technical system, in most cases, the creators of prints have to spend a lot of time and energy to become a superb technician to better control their creation. Once they leave the institution, it's difficult for their creation to sustain just like a fish leaving water.

This situation has indeed improved with the strengthening of technical exchanges and the emergence of professional art institutions such as Guanlan. However, the technical factor is still the objective existence that currently plagues the development of Chinese printmaking. Therefore, when the overall art of China begin to integrate into the process of reshaping the art of globalization, the stage of disenchantment of engraving of the prints has not yet been completed.

Go back to the topic of balance between technology and art The ability of technology is indeed the basic guarantee for the success of the work. Most of the print creation relies on equipment and process flow. For the various processes, the requirements for experience and strict operation are very similar to the laboratory or hand workshop. Productivity and indirectness bring a lot of loss of time to creation, so that half of the time of creation can be said to be tedious technical work. From the perspective of practitioners of print art, technicality is inevitably an important indicator of the aesthetics of printmaking. The indirectness of drawing and the rigor of technique are largely directed to the delicate and meticulous aesthetic tendency, which dominates the overall appearance of the print. But can the skillful and sophisticated technology bring contemporaryity for the block print art? Obviously, from the perspective of the curators of the 4th to the 5th International Block Print Biennial, the answer has been given. Technological advancement has indeed improved the possibilities of artistry and contemporaryity, but the key is to "achieving some kind of academic exchanges from the point of view of art, not "technology first."

\section{DISENCHANTMENT AND REENCHANTMENT}

Superb control force and planning ability is needed for the implement of printmaking techniques, but it is not the goal, but the means. Any technique or skill was invented to solve specific problems emerged in the past. To transcend the existing technologies and create new language, we must first have an understanding about the past, and have the imagination and cognition of the future. The innovation of language depends not only on the excellent technologies, but also on the wide vision and broad thinking. To truly make the block prints contemporary and innovative, and to make them no longer a self-entertainment in the "small circle", it is needed to achieve the disenchantment of technologies, that is, to make the technical factors return from the competitive shows to the backstage, and make the aesthetics and concepts become the protagonist again. Under the premise of continuously improving the technical system, it is necessary to make the techniques less conspicuous and the personal language and concepts more conspicuous in the works. 
In the field of Chinese paintings, the controversy between traditional ink and modern ink painting has been very fierce. Around the issue of whether or not to inherit the traditional Chinese ink, Chinese contemporary ink painting has experienced a process of disenchantment of traditional ink. There is no need to query the answer and the status and expressiveness of modern ink painting has affected all aspects of Chinese contemporary art now. The aesthetic appeal of the ancient using method of Chinese brushes has not disappeared in modern ink paintings, and it has been expanded and gained more recognition through the transformation in forms. The language innovation of traditional Chinese ink is contemporary, and its methodology and thinking has become more extensive. The disenchantment of traditional Chinese ink painting is to break down the barriers between traditional and modern aesthetic cognition. It has broken and reorganized the standards of Chinese traditional painting theory, and combined contemporary perspectives, concepts and aesthetics with the traditional standards, and retained the essence of tradition, such as the strength of using the Chinese brushes, the beauty of the Chinese brushes, etc., transforming the traditional Chinese ink painting from an external form into the contemporary aesthetic style with the traditional connotations.

Back to the field of block print, this paper sorts out the ways and means of disenchantment of block print technology and the understanding based on the impression of a lecture given by Chen Qi, a teacher from Central Academy of Fine Arts. Chen Qi is an artist who has been concentrating on woodblock-watermark for 30 years. After decades of thinking about artistic style and technology, he clearly proposed the idea of separating watermark-woodcut creation from painting. On the surface, it seems that he emphasizes the uniqueness and importance of technology, but the premise that cannot be ignored is that his opinion is based on the localization language of watermark-woodcut, which is different from the western block print style characterized by direct expression. Woodcut language is the first pattern to be eliminated from Western printing history, but it has developed into the most distinctive Chinese block print art. Its ontology language can best reflect the indirectness and procedural nature of block print. Chen Qi's block print has been pursuing the peak of watermark technology from fine expression of technology at the beginning, to the later application of digital technology and technical problem tackling in large size, to exploration of the latest mono print. If we use his early musical instrument series and ashtray series as a performance of showing off technology, watermark technology can be said to have reached the peak in his pursuit of huge works by using digital technology. However, in terms of the information conveyed by the works, technology consciously becomes the low-key background, while visual language and contemporaneity return to the front of the curtain. His latest mono print, starting from the characteristics of print and impression, pursues a high degree of integration of writing and printing technology to convey a spirit. What the audience see is the tension of writing and the unique expressive power of the impression. If it is not the onsite explanation, we can hardly imagine the difficulty of printing behind and the corresponding powerful control system it needs, from large prints to single prints, the workload and technical difficulty are calculated in terms of the amount of work. From the huge print to the mono print, the workload and technical difficulty are calculated by the amount of engineering. During the evolution of techniques and styles of the works, the technology behind is progressively improved. While the concept and spirit are strengthened, the technology is gradually invisible, finally realizing a state of unconventional. It can be said that Chen Qi's practice not only embodies the combination of tradition inheritance and contemporaryity and shows us the direction of tradition in the future, but also vividly deduces the real meaning of disenchantment of technology, that is, re-enchant artistic value.

\section{CONCLUSION}

Intaglio printing, relief printing, lithography, leaky printing, and digital printing come from different cultural and technical backgrounds and have different linguistic attributes. In the 7th century, because of the development of religious culture and prosperity of the economy, the block printing was invented in the Tang Dynasty; in the 16th century, European science and technology and humanistic thought promoted the revival of culture. Represented by Durer, a craftsman of making gold and silver jewellery, his more refined and direct copperplate etching replaced woodcut print; at the end of the 19th century, with the rise of commodity economy, lithography became a unique business card in French art. European copperplate etching, Chinese New Year watermark wood-block print, and Japanese Ukiyo are the combination of specific printing technology in different historical periods with humanities, art, new technique and new technologies. At this moment, we regard it as a classic traditional block print, which is the "contemporary" art of that time. The view we look at our traditions in the past also inspires us to think about the way we will look at ourselves today in the future. The artistic style at present may become a tradition in the future, but the premise that a work becomes a tradition in the future is that it must be able to represent the contemporary works. We are in an era of rapid renewal of science and technology and concepts, and constantly experiencing the thrill of technology updating and science and technology carnival. But we should return to a rational attitude after relaxing, and vision and soul will eventually become tired. People finally need to seek spiritual sustenance in art. As a creator, how to grasp the excellent conditions provided by the times and pour spiritual power into the works continuously is worth pondering. Therefore, I write this paper to comb the history of printing and encourage myself to cherish it.

\section{REFERENCES}

[1] E.H.Gombrich Art and Self-Transcendence, Contained in Ideals and Idols-The Position of Value in History and Art (2013), P119. (in Chinese)

[2] Seen in Yan Yu's Poem Theory of Canglang in the Northern Song Dynasty. (in Chinese)

[3] Platform for Presentation and Teasing-Comments on the 4th Guanlan International Print Biennial-Kang Jianfei. (in Chinese)

[4] Platform for Presentation and Teasing-Comments on the 4th Guanlan International Print Biennial-Kang Jianfei. (in Chinese)

[5] Platform for Presentation and Teasing-Comments on the 4th Guanlan International Print Biennial-Kang Jianfei. (in Chinese) 
[6] Research Significance of Biennial Data-the 5th Guanlan International Print Biennial-Kang Jianfei.(in Chinese)

[7] Ditto. 